\title{
Towards mining schedule optimisation constrained by geomechanics
}

\author{
N Saeidi MIRARCO, Laurentian University, Canada \\ D Millar MIRARCO, Laurentian University, Canada \\ L Fava MIRARCO, Laurentian University, Canada \\ M Cai MIRARCO, Laurentian University, Canada
}

\begin{abstract}
This paper reports work-in-progress that has the aim of incorporating geotechnical constraints on the optimisation of schedules of underground mine excavation activities. Optimal mine schedules are those for which the net present value (NPV) is maximised under a given financial model. The approach aims to consider the visco-elastic behaviour of rock when analysing the stability of excavations for constraint formulation.

Changes in deviatoric stress around multiple, sequential openings or excavations are mapped and are shown to be influenced by both changes in the time between excavation events and the sequence of excavating events. The results of this analysis are presented in this paper. The approach is predicated on a causality principle for mine seismicity which requires a time dependent response (visco-elastic or possibly visco-elasto-plastic) of the rock mass. This is potentially difficult to conceive for rock masses at great depth, but is nevertheless evidenced by mine seismicity records from deep level mining operations, some of which are reviewed in this paper. The output of these geotechnical sequencing studies will ultimately be cast as constraints on a mine schedule optimisation process.
\end{abstract}

\section{$1 \quad$ Introduction}

Underground mining consists of a series of development and stoping activities to extract ore from the host rock (Eberhardt et al. 1997). Mine scheduling aims to provide a timetable for these mining activities so as to derive the highest profitability. Practically, mine schedules can be disrupted by unexpected rock failure events. Stability of the rock mass is thus a key concern in underground mine scheduling; however, assimilating sequencing and timing constraints that aim to avoid or mitigate stress-related failures remains a challenge yet to be overcome. This paper introduces a methodology that may permit mine scheduling to include geotechnical stability constraints.

\section{$1.1 \quad$ Mine scheduling}

An underground mine consists of multiple stopes, cross-cuts, shafts, drifts, etc. which are produced as the result of mining activities. Mine schedule optimisation is concerned with timetabling mining activities to maximise the net present value (NPV). The costs of stoping and development activities are generally based on extracted tonnage or meters advanced. What makes two individual stopes with the same size in the same rock mass contribute differently to the NPV is the grade of the ore, the way they are mined and the timing of the extraction. In general, the process of mine schedule optimisation ensures that the ore mass with higher grade is reached sooner, and thus contributes more strongly to the NPV. This research must take into account the amount of resource available to complete the mining tasks. For example, development activity with a given fleet of equipment may mean that the total annual development advance is limited to a threshold value. Similarly, the production rate may be limited by hoisting capacity. Clearly, precedence constraints also need to be considered; stope access development must be completed before the corresponding stoping activity can start. 
The so-called 'chevron' (Figure 1) pattern for stope sequencing (Villaescusa 2003) can be adopted to apply additional precedence constraints on stoping activities, but it is potentially only applicable to a restricted set of geotechnical circumstances; this work aims to consider a more generalised approach.

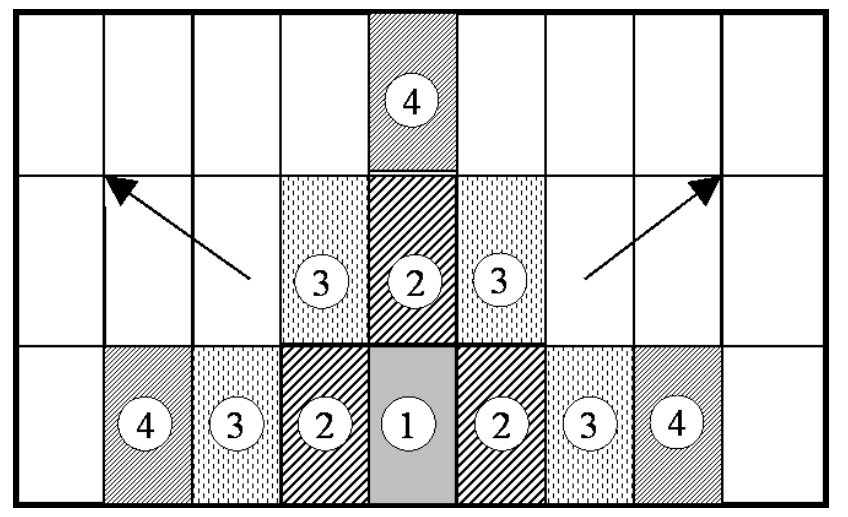

Figure 1 'Chevron', pillar-less centre-out stope sequencing (Morrison 1995)

\section{$1.2 \quad$ Stress}

Measuring the stresses which exist in rocks in the earth's crust has always been important to engineers and geologists (Ranalli 1987). Stress is a physical quantity that expresses the internal forces that neighbouring particles of a continuous material apply on each other (Brady \& Brown 1993). Stress existing in an undisturbed rock mass is related to the weight of the overlying layers, the rock properties, and the geological history of the rock mass. The stress field is disturbed by the creation of an underground excavation, and this disturbance can induce stress concentrations which may be high enough to reach the strength of the rock, causing instability by various mechanisms including the gradual closure of an excavation and rock burst (Hoek \& Brown 1987). In mining practice, information on the stress in the rock mass is necessary during mine planning (Louchnikov 2004). This work will consider how the sequence of stoping and development activities, defined in a mine schedule, will affect overstressing risk.

\subsection{Deformation}

Redistribution of stress leads to rock deformation. The nature of the deformation depends upon the constitutive behaviour of the rock or rock mass. Elastic behaviour is the tendency of a material to deform as it is stressed and regain its original shape and size upon removal of the stress. Hooke's Law states that, for small deformations of an object, the displacement or size of the deformation is directly proportional to the deforming force or load. In rock mechanics, Hooke's law is expressed in terms of stress and strain. Stress is the force per unit area within a material that develops as external forces are applied. Strain is the deformation produced by stress (Houwink et al. 2009). In an elastic medium, one can expect the deformation response to be contemporaneous with the stress redistribution. If a deformation response has any measure of time dependency, then the rock or rock mass constitutive behaviour is not purely elastic.

Visco-elastic behaviour is the tendency of a material to exhibit both viscous and elastic characteristics when deforming under stress. Viscous behaviour implies a time-dependent fluctuation in strain (Meyers \& Chawla 1999). Elastic behaviour implies a recovery of shape and size upon unloading. Visco-elasticity implies the same with time required for the recovery of shape and size.

\section{$2 \quad$ The importance of time-dependent rock response for mine scheduling}

As the result of changes in the state of stress, rock masses deform to reach a new equilibrium. There are numerous examples of rock engineering and rock mechanics analyses that ignore time-dependent response, despite it being a fundamental rock and rock mass behaviour. As an example, consider Bieniawski's rock mass classification system (Bieniawski 1976) where the meaning of the rock mass classes are expressed in time dependent terms, i.e. the 'stand up time' (Brady \& Brown 1993), which is the length 
of time for an opening in a rock mass to remain stable. The importance of considering time-dependent behaviour in rock masses comes to the care when the principal objective of investigation is to determine timings, as is the case with mine scheduling. This deformation is a time dependent procedure which may lead to rockburst over time. Creep refers to time dependent deformation, defined as a continuous deformation under constant stress with no further disturbance (Malan 1999). The study of creep has been assigned low importance in hard rock mining due to its low rate of progression (Dusseault \& Fordham 1993). However, early research on South African gold mining practices recognised the importance of time-dependent rock responses in studying rock stability (Denkhaus et al. 1958; Roux \& Denkhaus 1954). Later, Linkov (1996) highlighted the importance of time-dependency in stability analysis.

Adams and Jager (1980) studied fracture zone growth in progressive stoping and observed that postponing the advance of the stope face for two weeks could avoid the creation of new fractures, and this clearly suggests a time-dependent response. King et al. (1989) studied rock response after blasting in deep level South African mines and observed that after each blast, deformations included an instantaneous (elastic) response followed by a decelerating visco-elastic response. The difference between sudden loading on a body of a rock mass and the subsequent relaxation of the stress field within that body, manifest through time dependent deformation (as illustrated in Figure 2) that needs to be carefully considered in mine activity scheduling studies because the stability of the rock mass is directly affected by the distribution of stress arising from excavation activities (Malan 1999). As further reported by Malan (2003), the rate of mining activities, largely ignored previously, was found to be an important factor in time-dependent deformation responses around deep tabular excavations. Based on a study of the effect of the mining rate on the total amount of steady-state closure (secondary creep behaviour) at a particular point in the stope, it was found that the rate of steady state closure decreased as the number of blasts per week increased (Malan 2003).

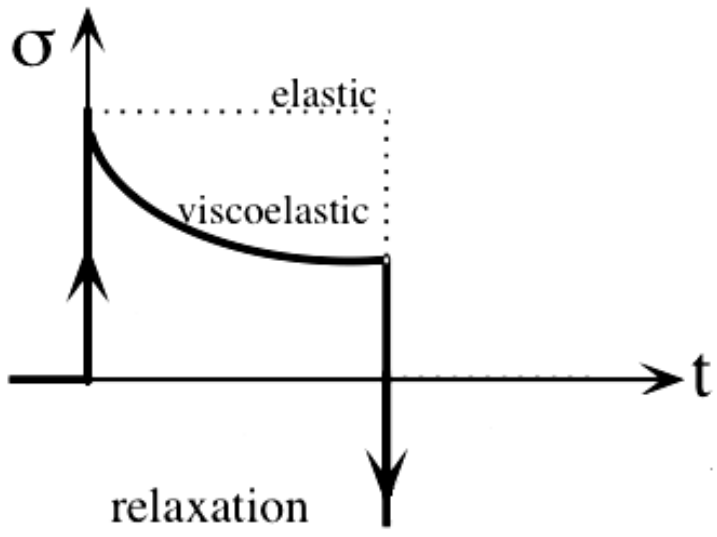

Figure 2 Sudden stress loading and the subsequent relaxation (Lakes 2009)

Figure 3 is the creep curve for a sample of Barnsley Hards Coal obtained from Terry and Morgans (1958) as reported by Millar and Jiao (1994) at two different scales. Both vertical axes refer to the displacement of the coal sample under constant load. The horizontal axis refers to the time of deformation. Line curve shows deformation on the left axis scale; the dots show the same deformation on the right axis scale. Clearly in the case, the rock appears to behave elastically over a length scale of $0.5 \mathrm{~mm}$, developing a large, near instantaneous deformation at $\mathrm{t}=0$, with the displacement appearing to remain constant thereafter, and yielding a stepped profile (or castellated if followed by an unload stage). However, examining the same deformation response on an expanded scale clearly reveals the time-dependent deformation and visco-elastic response. 


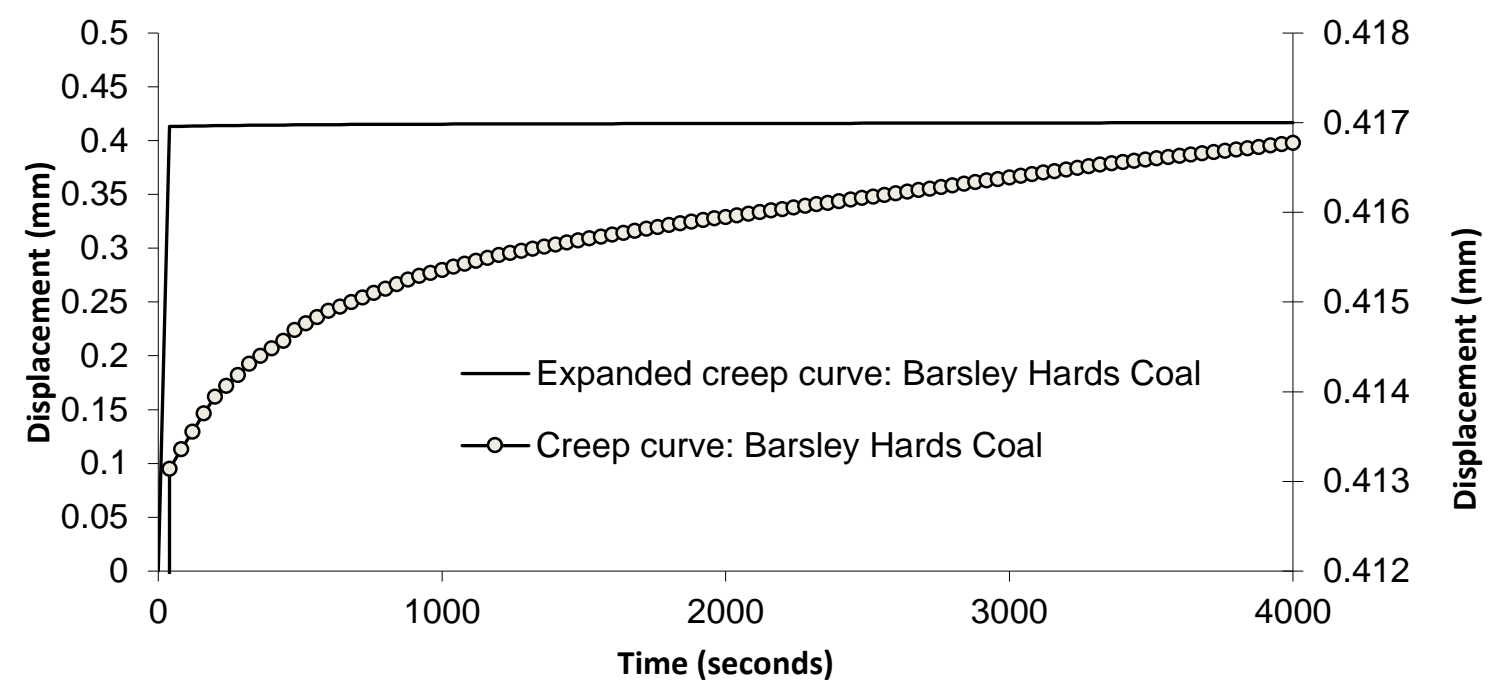

Figure 3 Experimental Barnsley Hards Coal creep curve in two different scales (Millar \& Jiao 1994)

Figure 4 is a magnitude-time chart for seismic events at the Big Bell mine, representing three years of mining (Beneteau 2012). The record features a one year period of shutdown when no or very little mining activity took place. The rate of events during the production shutdown is low but, more importantly, the mine was clearly still seismically active during this time. Without a model of seismicity causality that includes time dependent rock constitutive behaviour, it is difficult to explain why these events occurred. When the mine was operational, it is clear from Figure 4 that the frequency of events increased. If a seismicity causality model involving time-dependent behaviour has to be called upon to explain events during the shutdown, why should this same model not apply during operations?

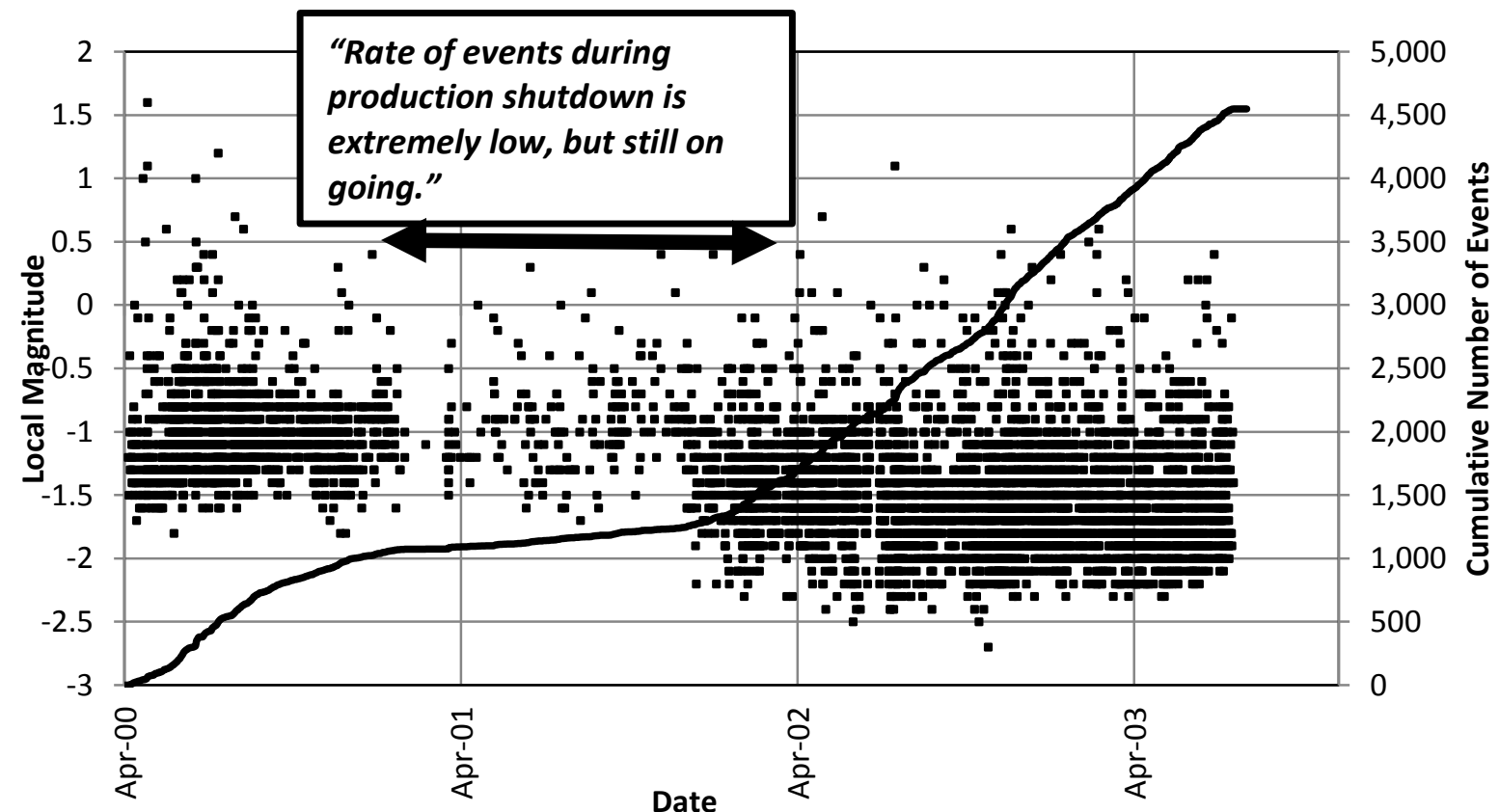

Figure 4 Magnitude - time chart for microseismic events at Big Bell mine (Beneteau 2012)

\section{Elastic responses to the sequence and duration of mining activities}

Knowledge of the stress condition in the rock mass is a key element in designing an underground excavation (Louchnikov 2004). Deep mines face significant challenges with problems that are directly 
concerned with stress that may destabilise mine openings. All types of rock failure are ultimately related to stress conditions in the rock mass (Louchnikov 2004). It is important to realise that the stress does not 'go away'; it is simply redistributed (Ranalli 1987). One can conceive of two phases of rock stress: (1) the stresses existing in the rock before any mine openings are made, and (2) the rock stresses altered because of the introduction of mine openings (Hoek \& Brown 1987).

Stress analysis has multiple objectives: (1) to determine the effect of the different shapes upon the stress concentrations at the boundaries of the openings for different states of initial stress in the rock; (2) to determine the best suited shape (smallest stress concentration induced in the surrounding rock) for each of the initial stress conditions within the rock mass; and (3) to determine approximately the stress which exists around actual mine openings (Ranalli 1987).

\subsection{Stress studies in sequence of excavations}

In this section, elastic stress analyses are presented to show how the sequence and duration of mining activities affected the stress path and how manipulation can lead to avoidance of overstressing at certain locations within the surrounding rock mass. There are many instances underground where mine openings occur so close together that the introduction of one opening affects the stress concentrations around another. This condition is important, because stress concentrations are increased when two or more openings are adjacent. In general, the resulting increase of stress surrounding multiple openings increases the risk of failure of one or many of them (Ranalli 1987). The following figures (Figures 5 to 10) show the stress distribution around three phased excavations: square (first), circle (second), diamond (third), using Phase $^{2}$ software (Rocscience inc. 2014a) with a field stress of $\sigma_{1}=100 \mathrm{MPa}$ vertically and $\sigma_{3}=50 \mathrm{MPa}$ horizontally. Phase ${ }^{2}$ was used because it was a simple, accessible tool which could undertake elastic analyses very quickly.

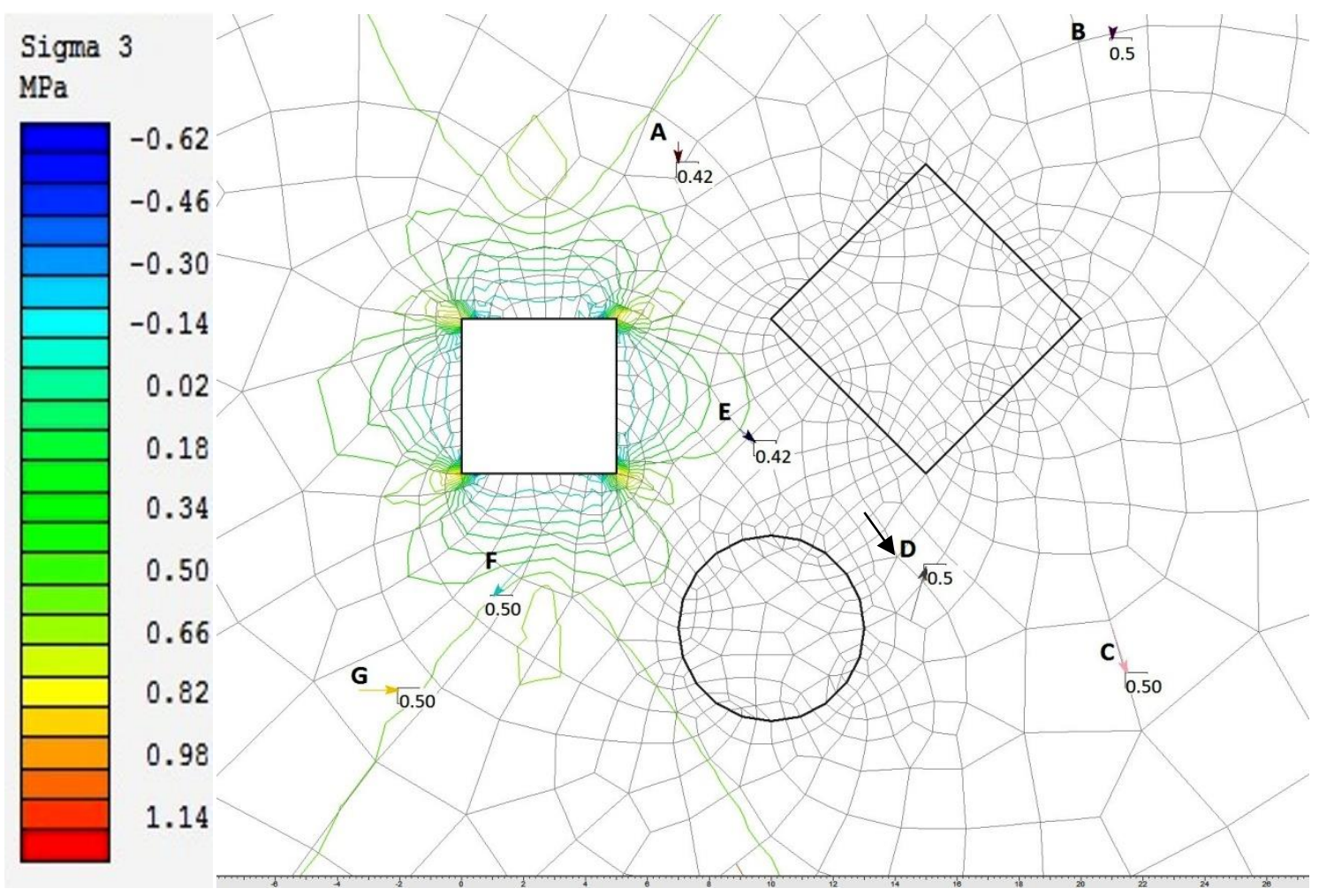

Figure $5 \quad \sigma_{3}$ (minimum principal stress) distribution after the excavation of the square opening $(\times 100), K=0.5$ 


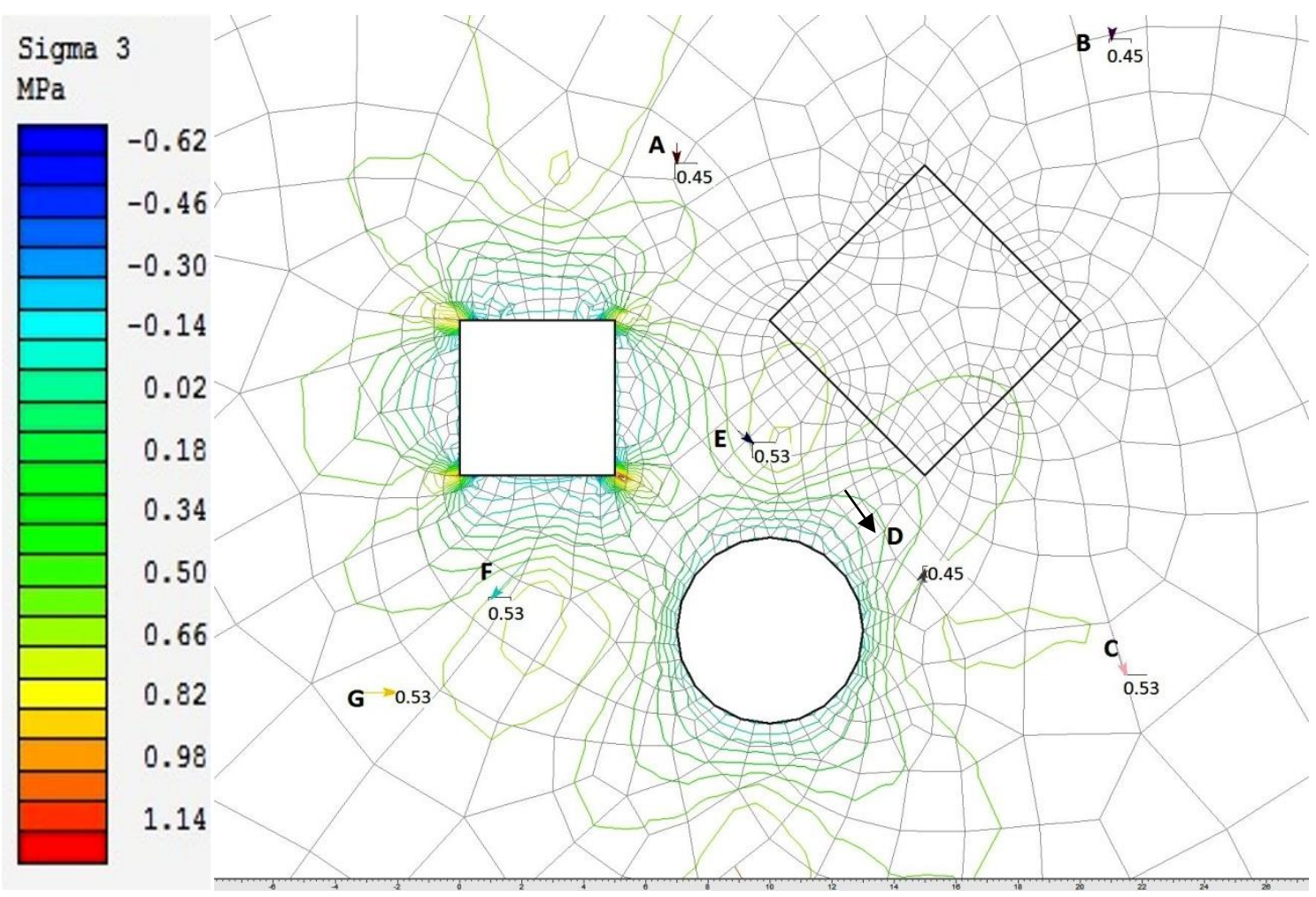

Figure $6 \sigma_{3}$ (minimum principal stress) distribution after the excavation of the square and circle shaped openings $(\times 100), K=0.5$

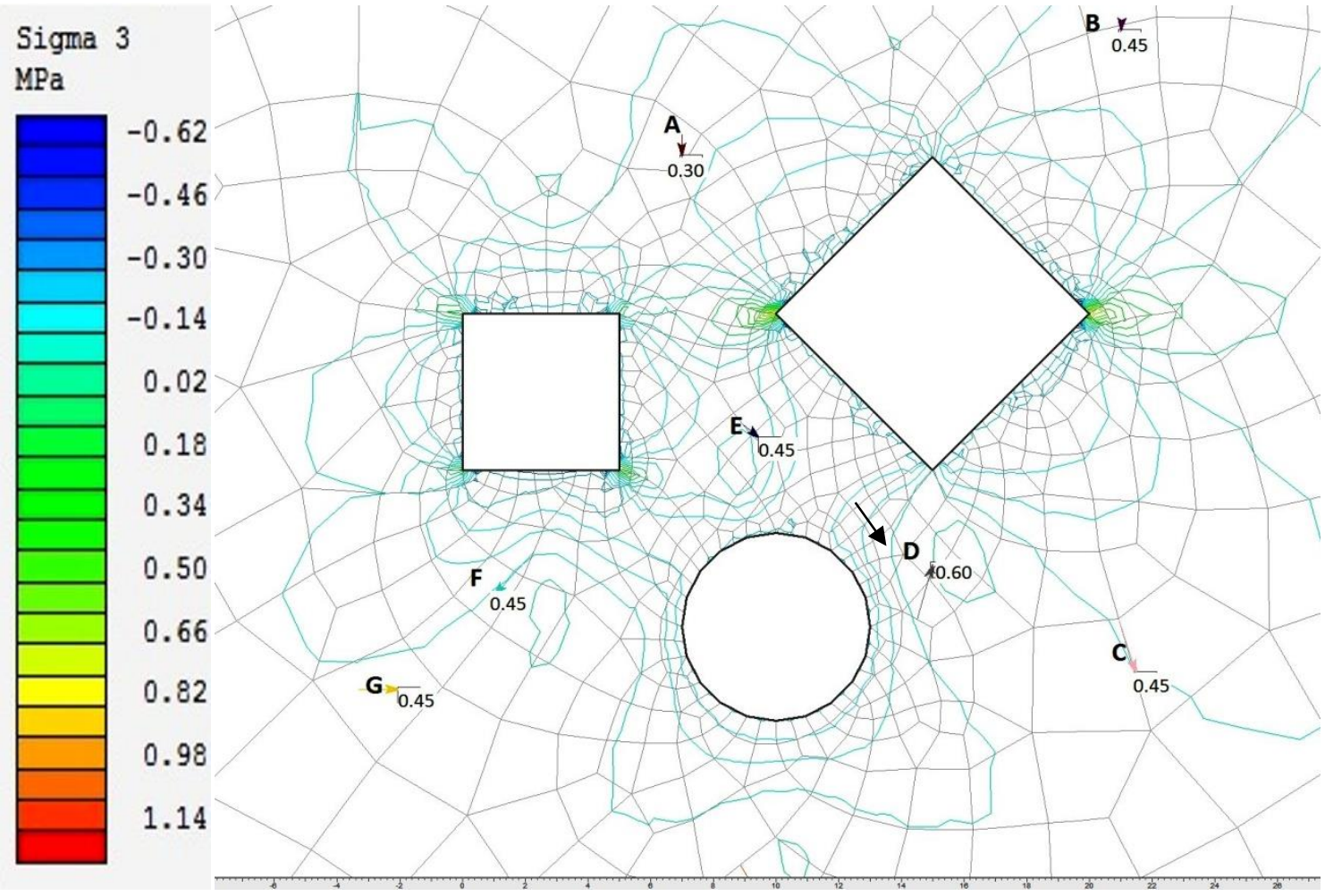

Figure $7 \sigma_{3}$ (minimum principal stress) distribution after the excavation of the square, circle and diamond shaped openings $\left(x_{100}\right), K=0.5$ 


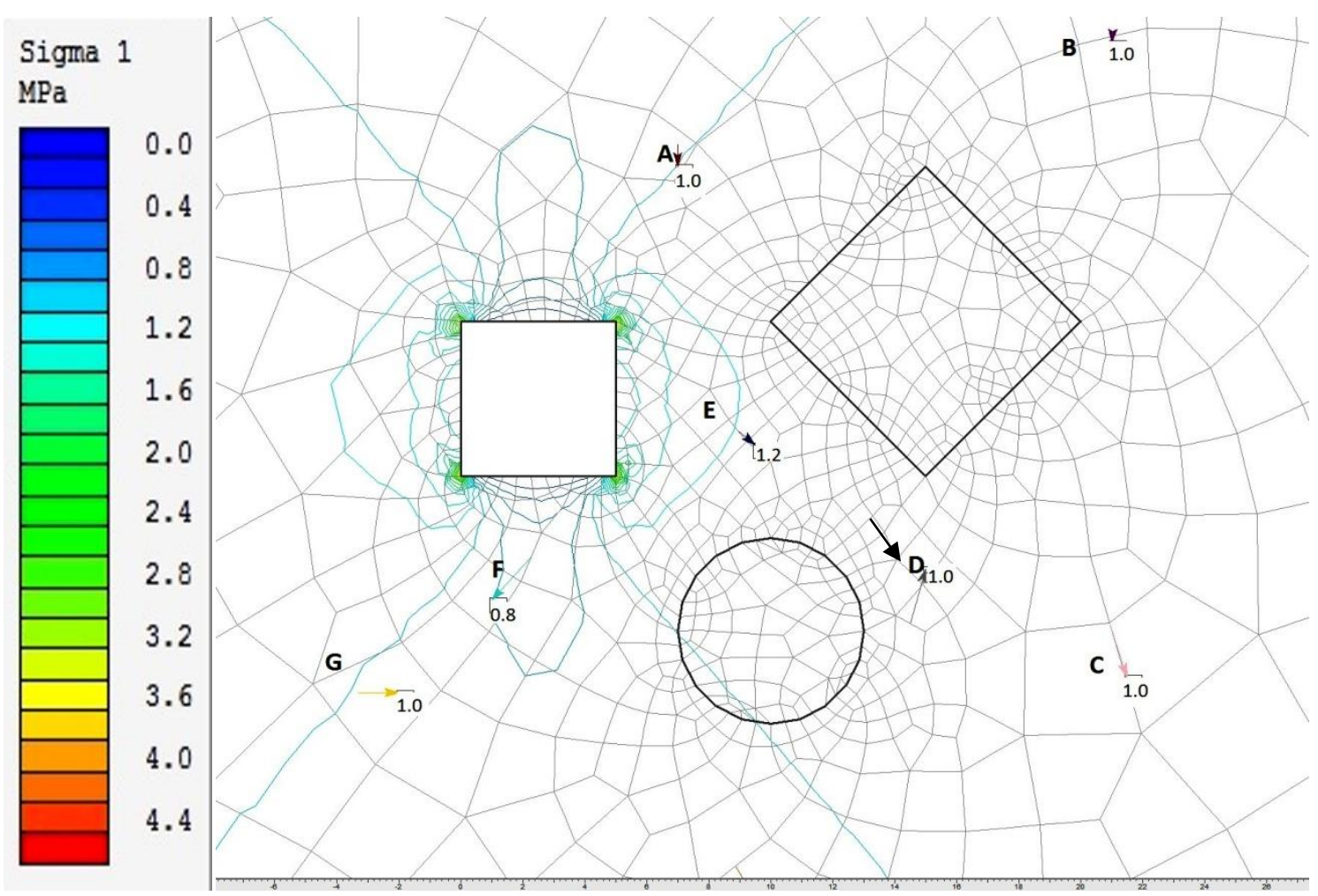

Figure $8 \sigma_{1}$ (maximum principal stress) distribution after the excavation of the square opening $(\times 100), K=0.5$

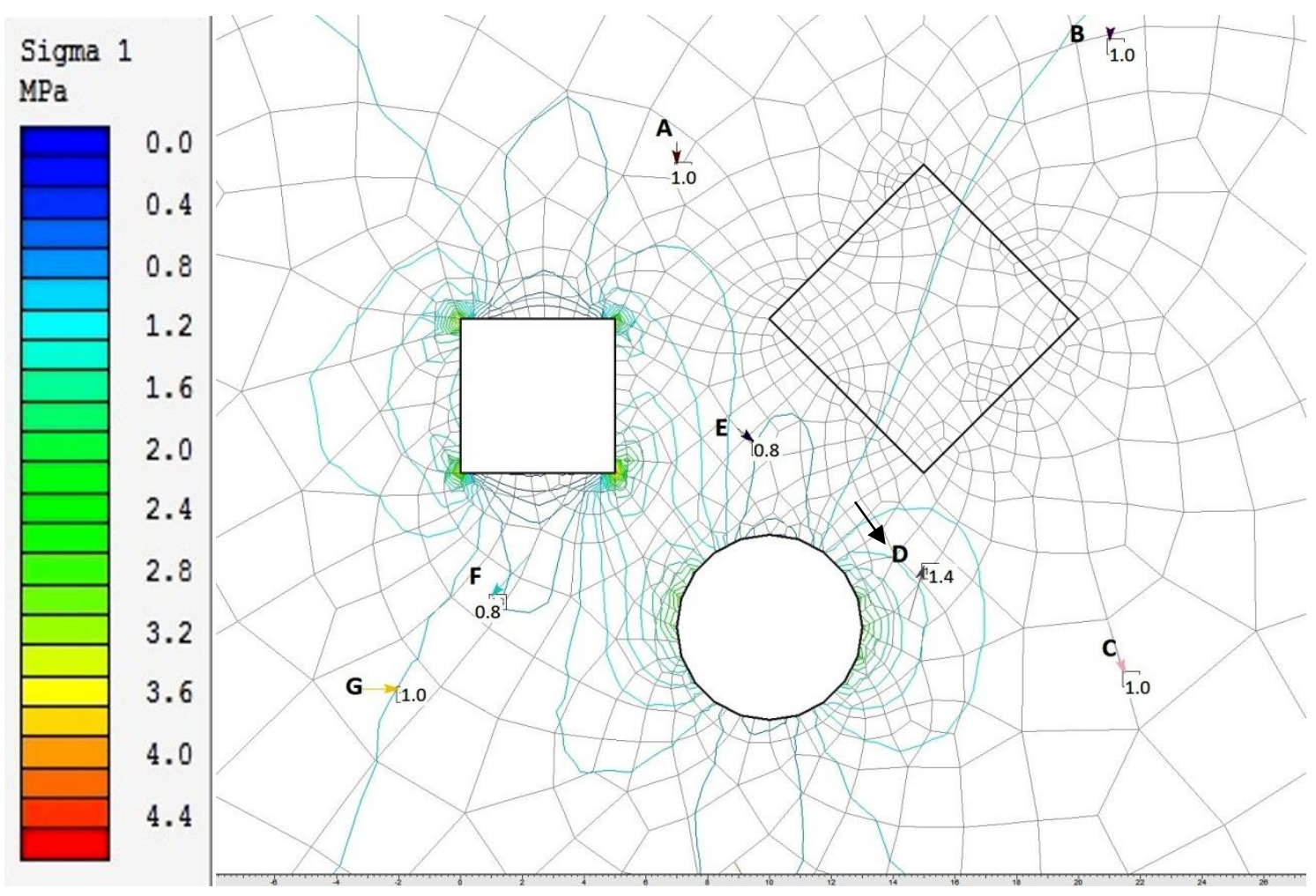

Figure $9 \sigma_{1}$ (maximum principal stress) distribution after the excavation of the square and circle shaped openings $(\times 100), K=0.5$ 


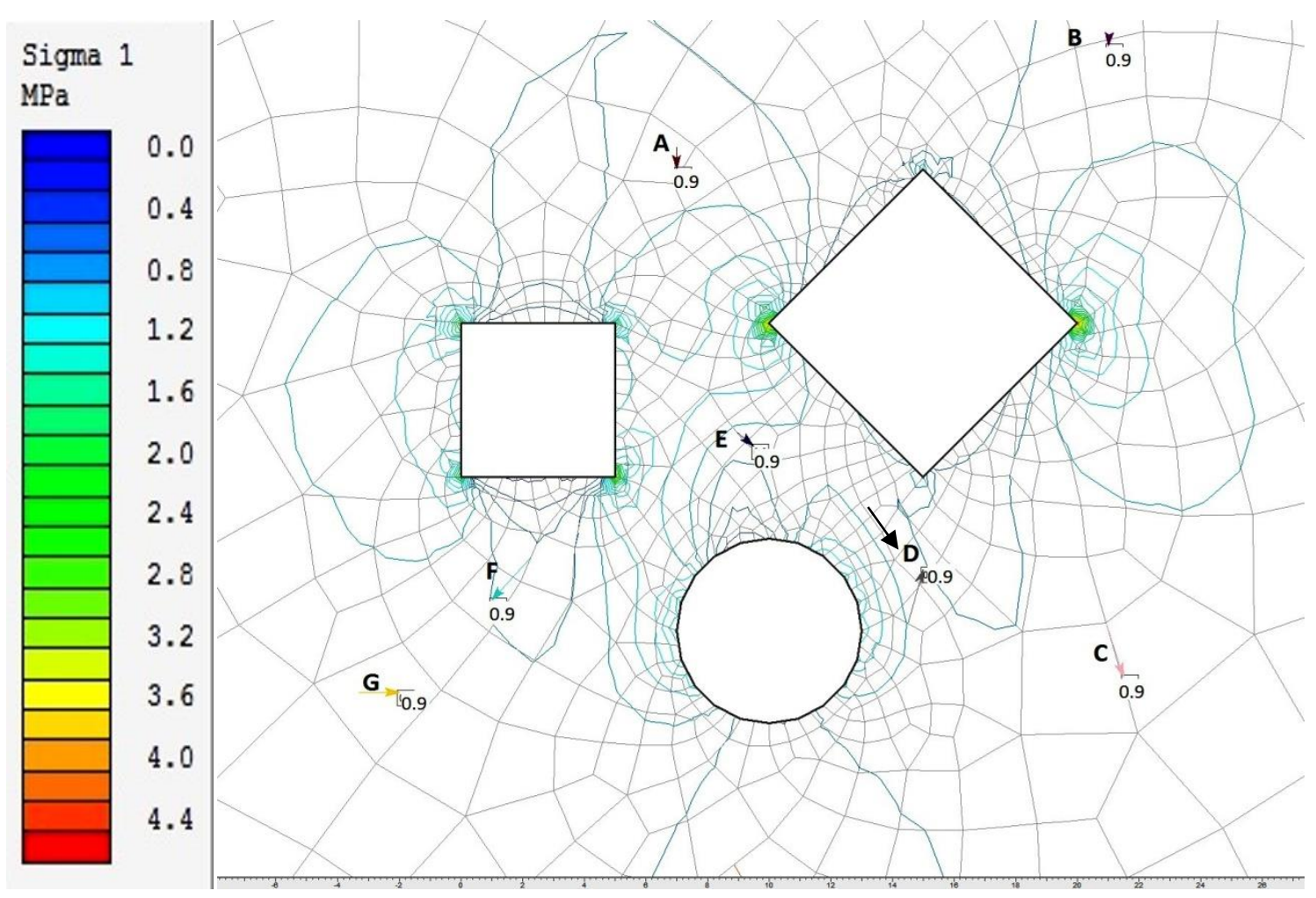

Figure $10 \sigma_{1}$ (maximum principal stress) distribution after the excavation of the square, circle and diamond shaped openings, $\mathrm{K}=0.5$

The effect of the sequences of excavation was assessed by 'monitoring' the instantaneous changes in the stress field as each excavation was created in turn. Several locations within the modelled domain were chosen as locations and a simulated time series of stress state is prepared. For point $D$ in Figures 5 to 10 (with black arrow), the time series produced is presented in Figure 11.

The vertical axis refers to principal stress component magnitudes at point $D$ and the horizontal axis refers to time. Excavation events are presumed to create step changes in the profile, as suddenly excavated openings lead to sudden redistribution of stress in elastic media. Based on Table 1, after excavating the square shaped opening, $\sigma_{1}$ and $\sigma_{3}$ at point $D$ are approximately equal to 100 and $50 \mathrm{MPa}$, respectively, which suggests that the excavation has no effect on the state of stress at point $D$, which is outside the zone of influence of the square excavation. When the circular opening is excavated (assumed to be timetabled at the beginning of week 3 ), the state of stress at point $D$ is changed, and it changes again in week 6 when the diamond shaped opening is excavated.

Deviatoric stress is computed for each timetabled phase to study the likelihood of shear failure caused by excavations. This is reported in Table 1 for all points (A to G) marked in Figures 5 to 10 in two different sequences of excavation, and the time series of deviatoric stress is shown in Figure 12. 


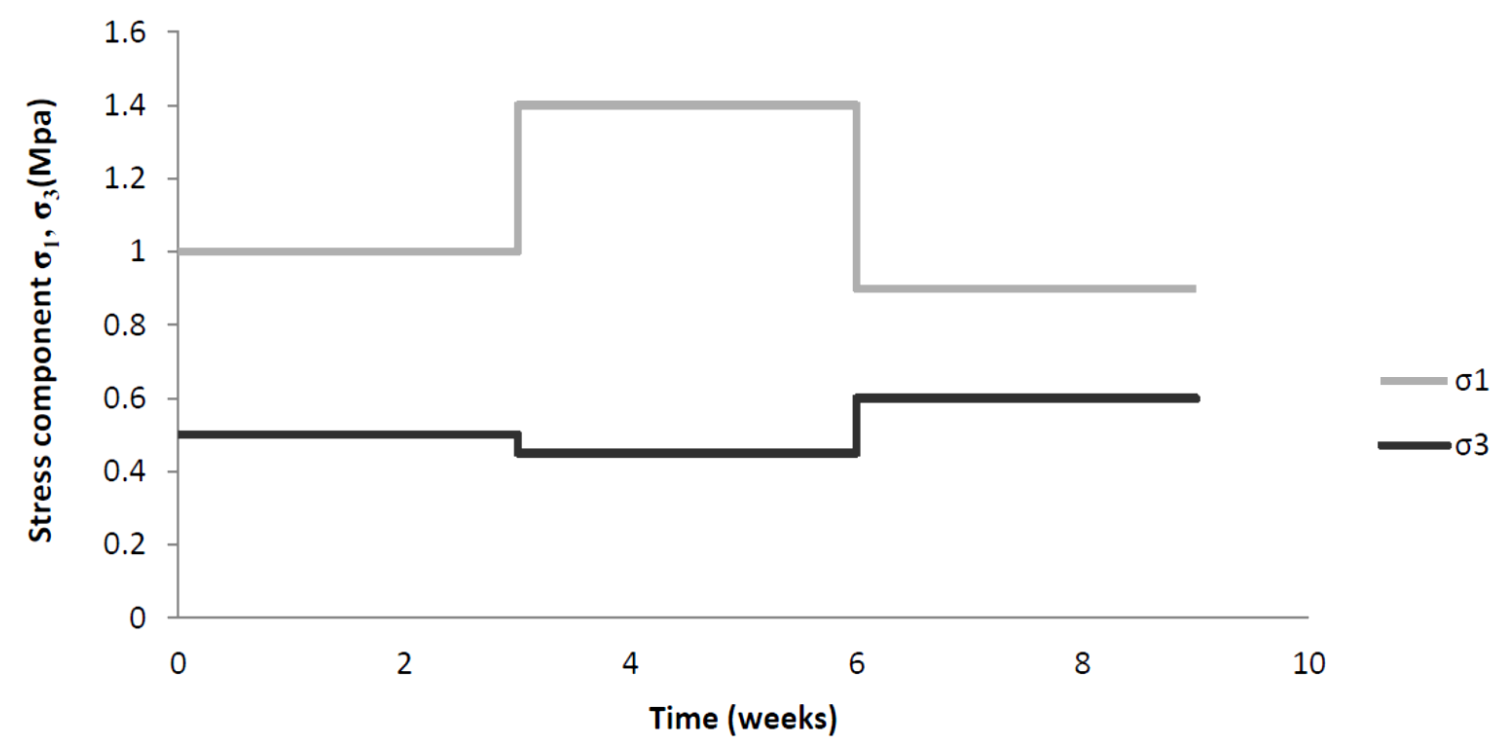

Figure $11 \sigma_{1}$ and $\sigma_{3}$ changes in the process of excavating new openings at point $D(\times 100)$

Table 1 Deviatoric stress $\left(\sigma_{d}\right)$ at points $A$ to $G$ in two different sequences of excavation, illustrated in Figures 5 to 10. Stress is measured in MPa, and field stresses are $\sigma_{1}=100$ $\mathrm{MPa}$ and $\sigma_{3}=50 \mathrm{MPa} ; \mathrm{K}=0.5$

\begin{tabular}{|c|c|c|c|c|c|c|c|c|c|c|c|c|}
\hline \multirow{3}{*}{ Point } & \multicolumn{9}{|c|}{ Sequence 1} & \multicolumn{3}{|c|}{ Sequence 2} \\
\hline & \multicolumn{3}{|c|}{ Square } & \multicolumn{3}{|c|}{ Circle } & \multicolumn{3}{|c|}{ Diamond } & \multirow{2}{*}{\begin{tabular}{|c|} 
Square \\
$\sigma_{d}$
\end{tabular}} & \multirow{2}{*}{$\frac{\text { Diamond }}{\sigma_{d}}$} & \multirow{2}{*}{$\frac{\text { Circle }}{\sigma_{\mathrm{d}}}$} \\
\hline & $\sigma_{1}$ & $\sigma_{3}$ & $\sigma_{d}$ & $\sigma_{1}$ & $\sigma_{3}$ & $\sigma_{d}$ & $\sigma_{1}$ & $\sigma_{3}$ & $\sigma_{\mathrm{d}}$ & & & \\
\hline$A(7,15)$ & 100 & 42 & 58 & 100 & 45 & 55 & 90 & 30 & 60 & 54 & 120 & 90 \\
\hline $\mathrm{B}(21,19)$ & 100 & 50 & 50 & 100 & 45 & 55 & 90 & 45 & 45 & 48 & 45 & 45 \\
\hline$C(21.5,-1.5)$ & 100 & 50 & 50 & 100 & 53 & 47 & 90 & 45 & 45 & 48 & 45 & 45 \\
\hline$D(15,2)$ & 100 & 50 & 50 & 140 & 45 & 95 & 90 & 60 & 30 & 50 & 0 & 30 \\
\hline$E(9,6)$ & 120 & 42 & 78 & 80 & 53 & 27 & 90 & 45 & 45 & 74 & 135 & 90 \\
\hline$F(1,1)$ & 80 & 50 & 30 & 80 & 53 & 27 & 90 & 45 & 45 & 28 & 55 & 45 \\
\hline$G(-2,-2)$ & 100 & 50 & 50 & 100 & 53 & 47 & 90 & 45 & 45 & 48 & 45 & 45 \\
\hline
\end{tabular}

Most importantly, Figure 12 shows that as new openings are excavated, deviatoric stress can reduce as well as increase as new excavations are introduced. A notional strength of the medium is shown as dotted line in Figure 12. It is assumed that if the deviatoric stress passes this line, the risk of instability of point $D$ is high. Figure 13 shows the deviatoric stress history at point $D$ considering a different sequence of excavations (square, diamond, and circle). It is clear that for elasto-plastic behaviour, the sequence of excavations may affect the stability of the rock. The deviatoric stress curve does not cross the dashed green line, suggesting that the risk of instability is significantly reduced. Note also that the state at the start of the sequence and the end of the sequence are the same between Figures 12 and 13; the end stress state may be the same, but the loading path is different. Although simplistic in analysing stress change using an elastic model, the insight from the result is clearly very important for mine scheduling. 


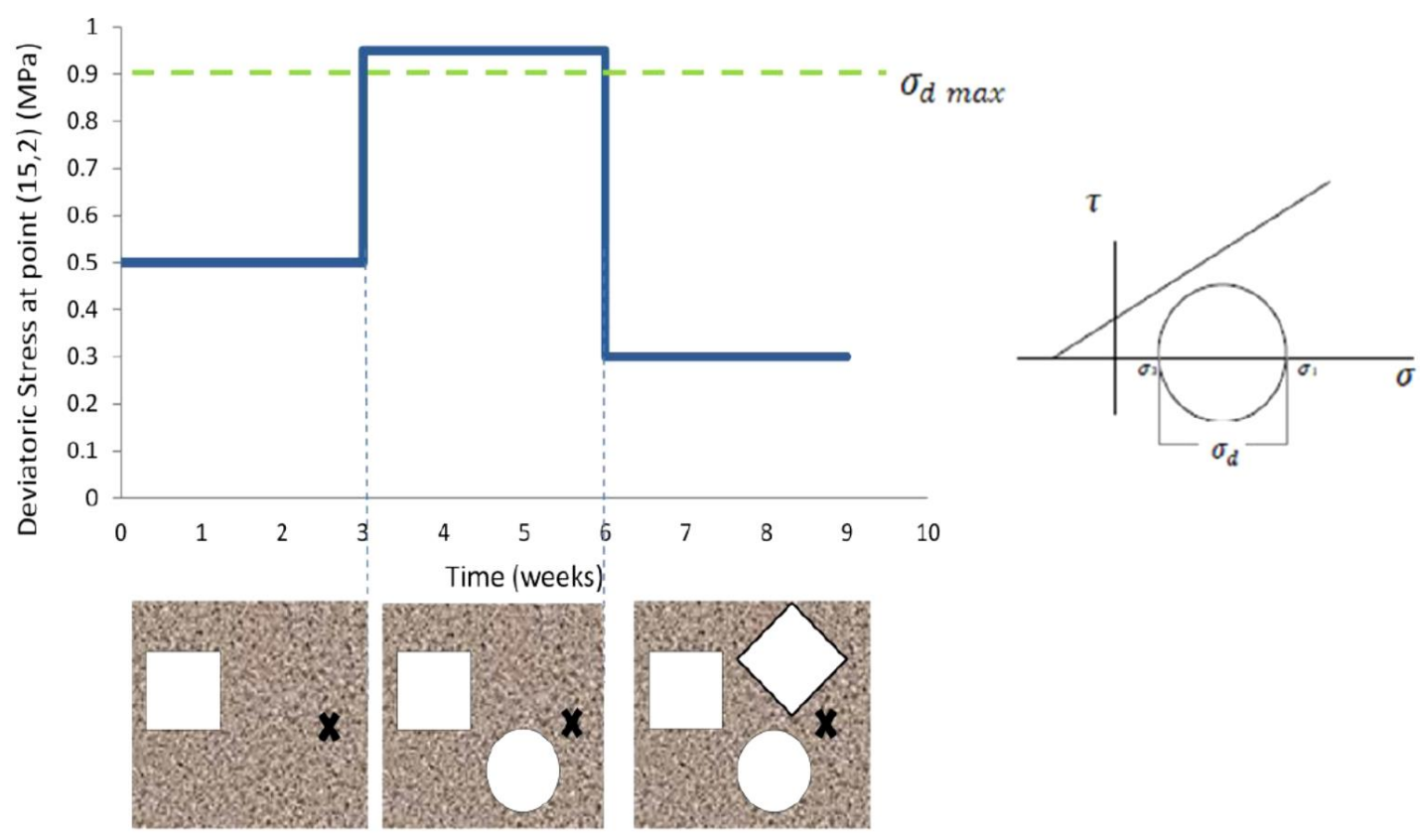

Figure 12 Deviatoric stress $\left(\sigma_{d}=\sigma_{1}-\sigma_{3}\right)$ at point $D$ in the process of excavating new openings $(\times 100)$
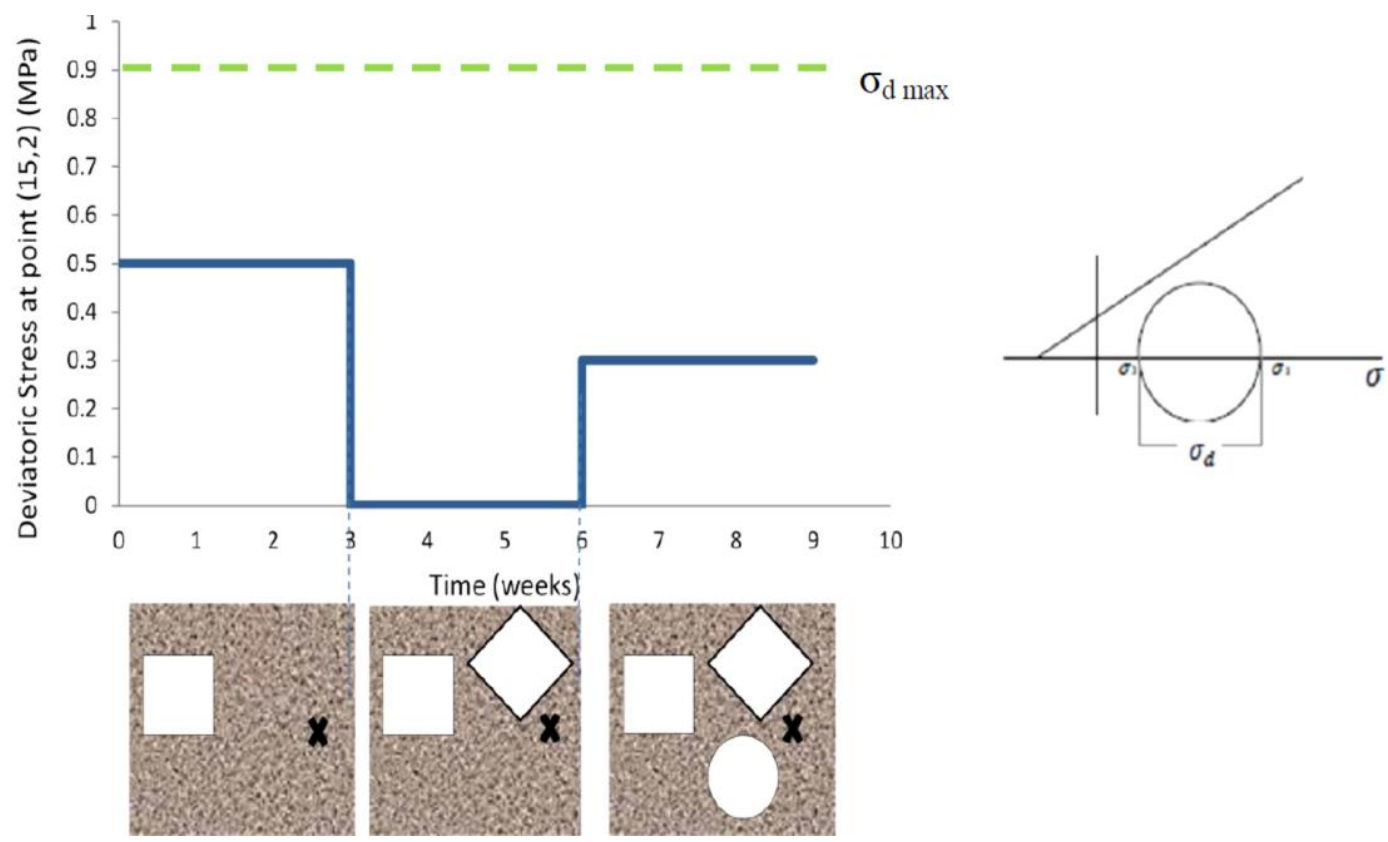

Figure 13 Deviatoric stress $\left(\sigma_{d}=\sigma_{1}-\sigma_{3}\right)$ at point $D$ in the process of excavating new openings $(\times 100)$

\subsection{Stress studies in alternation of duration between activities}

In Figure 14 the original sequence of excavations is maintained (as in Figure 12), but consideration is given to the effect of varying the duration between excavation events. Again, all excavations are assumed to be suddenly made to yield an instantaneous elastic deformation response, which is characteristically 'castellated'. Figure 14 shows that the circular opening is excavated at week four (rather than week three as before) and the diamond opening is excavated at week five (rather than week six as before). Nothing has changed significantly between Figures 12 and 14; the risk of failure is still the same, but it occurs at a different time and for a different duration. Although the deviatoric stress exceeds the notional strength threshold, we adopt this measure simply as an instability risk indicator, rather than definitive statement 
that failure will occur. It should be noted that the 'no-different' observation is a consequence of elastic constitutive behaviour.
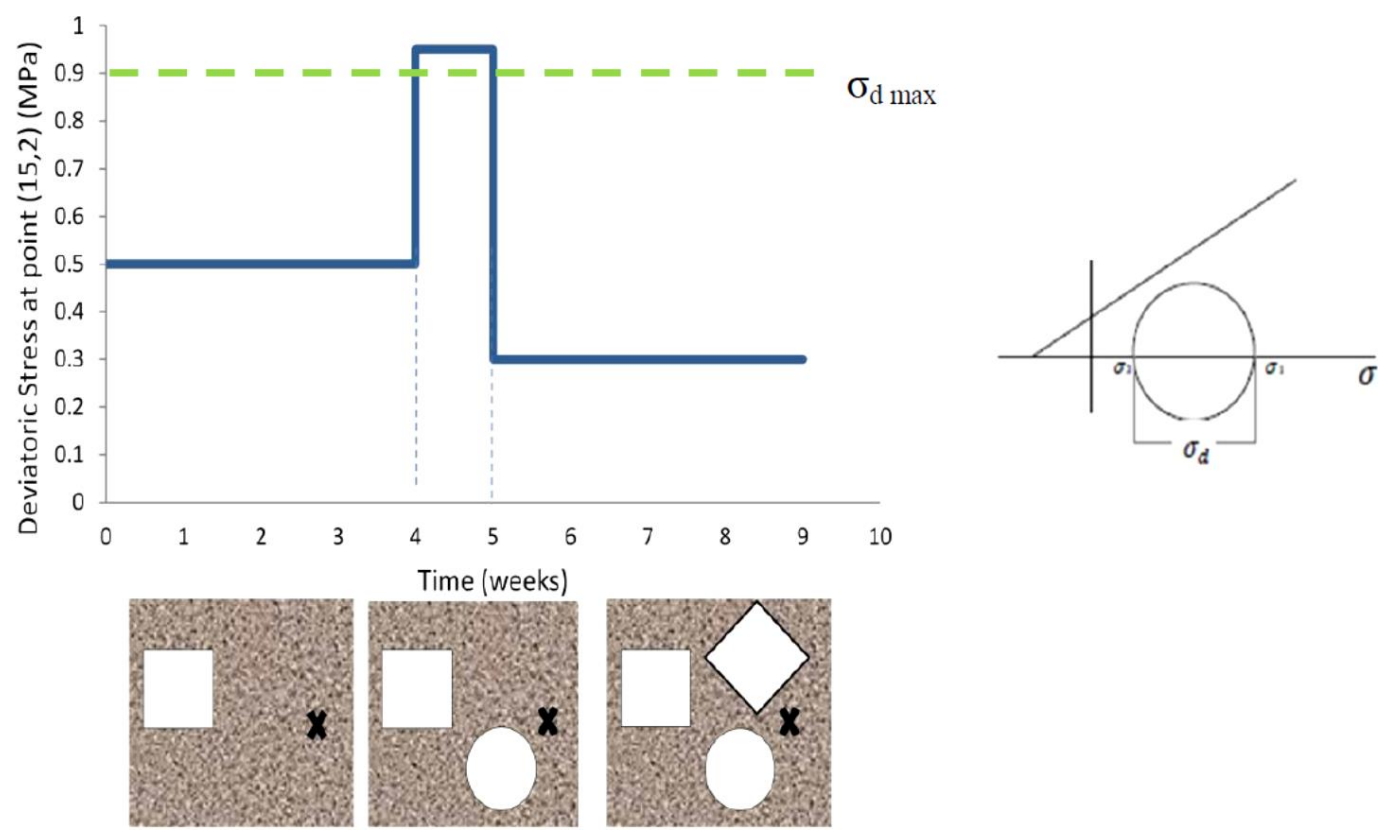

Figure 14 Deviatoric stress $\left(\sigma_{d}=\sigma_{1}-\sigma_{3}\right)$ in the process of excavating new openings at point $D$ $(\times 100)$

\section{$4 \quad$ Interaction between scheduled activity duration and visco-elastic deformation}

In the previous section it was shown that while the rock is assumed to behave elastically only, the effect of a change in duration of a mining activity (or rather the duration between mining activities) on the risk of instability was nil. When a time-dependent deformability response is assumed, as in the case in this section, the effect of a change in duration may be dramatic.

Figure 15 shows a schematic strain-time curve showing deformations at a specific point in a rock mass, as sequence of mining activities are undertaken.

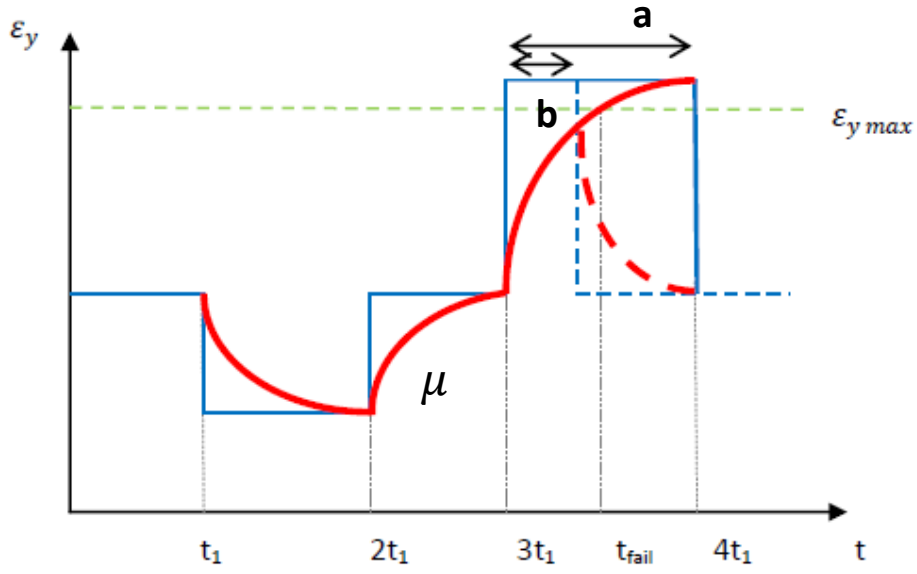

Figure 15 Strain-time curve at point $D$ in Figures 5 to 10, subjected to the changing force in time duration $\left(0<\mathrm{t}<4 \mathrm{t}_{1}\right) \cdot \mu=$ viscous coefficient

The blue line in Figure 15 shows the expected response considering the rock mass to be purely elastic. It arises from a series of stress analyses reflecting the sequence of mined activities; information on the time axis refers to the schedule of excavating new openings adjacent to the point of consideration. Its 
castellated appearance is a result of instantaneous elastic deformations in response to instantaneous loading of the rock at the point, as the excavations are produced. The strain may reduce or increase as was the case in Figure 13. The green dashed line refers to a maximum permissible strain of the rock mass at the point of consideration. At $t_{1}$, it is supposed that a development activity in an adjacent opening introduces a time-dependent response that asymptotically converges on the expected elastic deformation, as time after the excavation event proceeds. At $t=2 t_{1}$, another advance of an adjacent opening occurs, and this gives rise to another time-dependent deformation response (to $t=3 t_{1}$ ). At $t=3 t_{1}$, a large perturbation occurs, the outcome of which depends upon the period of time to the next event. If this duration is a, then the time dependent response leads to the threshold strain being exceeded at $t_{\text {fail }}$. On the other hand, if the activity schedule is modified (a management decision), so that the duration is $b$, then the risk of exceeding the threshold is avoided.

The time-dependent behaviour of the rock can be investigated by undertaking a creep test which is performed by applying a constant stress to the material and analysing the strain response of the system with time. Alternatively, time-dependent duration of an in-service excavation can be back-analysed to determine creep parameters. Knowledge of creep parameters may allow modification of elastic response curves, such that visco-elastic deformation behaviour can be considered in the analysis.

\section{$5 \quad$ Future of the research}

The focus on development of a geotechnical failure risk indicator for use in constraint formulation in mine schedule optimisation, conceptually outlined in this paper, has focused on elastic analyses for good reason. Linear elasticity permits the principle of superposition to be used to determine the cumulative effect on a stress field of a sequence of mine excavation activities. Mine schedules may involve thousands of activities such that an approach aiming to model visco-elastic behaviour of complete sequences and durations is intensely impractical. However, 'pre-computation' of stress and strain induced by the mining activities considered independently, but within the same computation domain, permits the resulting fields to be superimposed in varying orders so that the castellated failure risk indicator profile can be completed efficiently. The castellated profiles may be 'de-castellated' through knowledge of a viscous coefficient to modify the deformation response such that it (crudely) approximates the visco-elastic behaviour of rocks.

Figure 16 is a scheme showing how the geotechnical analyses are planned to be automated to produce failure risk profiles in mine schedule optimisation procedures. The scheme involves two loops: one is presented in red which is focuses on stress analysis in sequences of mining activities considering elastic response. This loop is assumed to work by manipulation of default stress analysis employed in Examine3D (Rocscience inc. 2014b). The other is presented in blue and is for viscous analysis and its effect on mine schedule. The second loop is hoped to cast the result in an automated fashion to use geotechnical analysis results as constraints to a mine schedule optimisation process. The schedule optimisation process will be undertaken using a genetic algorithm by the Schedule Optimization Tool (SOT) (Maybee et al. 2010). Applied constraints will ensure high-value mine schedules with upgraded aspects of rock mass stability.

\section{Conclusion}

The ultimate objective of this research is to produce a high value schedule which increases the profitability of the mining activities as well as decreasing the risk of rock failure. The geotechnical failures can cause delays in the schedule and consequently loss of value. A core hypothesis of the work is that there is a time dependent aspect of rock behaviour that leads to instability, as well as a dependence of geotechnical instability upon the sequence and duration between mining activities. Geotechnical studies, including stress analysis studies and studies of time dependent behaviours of rock, provide the required constraints in order to re-evaluate mining activities of an optimised mine schedule that minimise the risk of rock mass failures. 


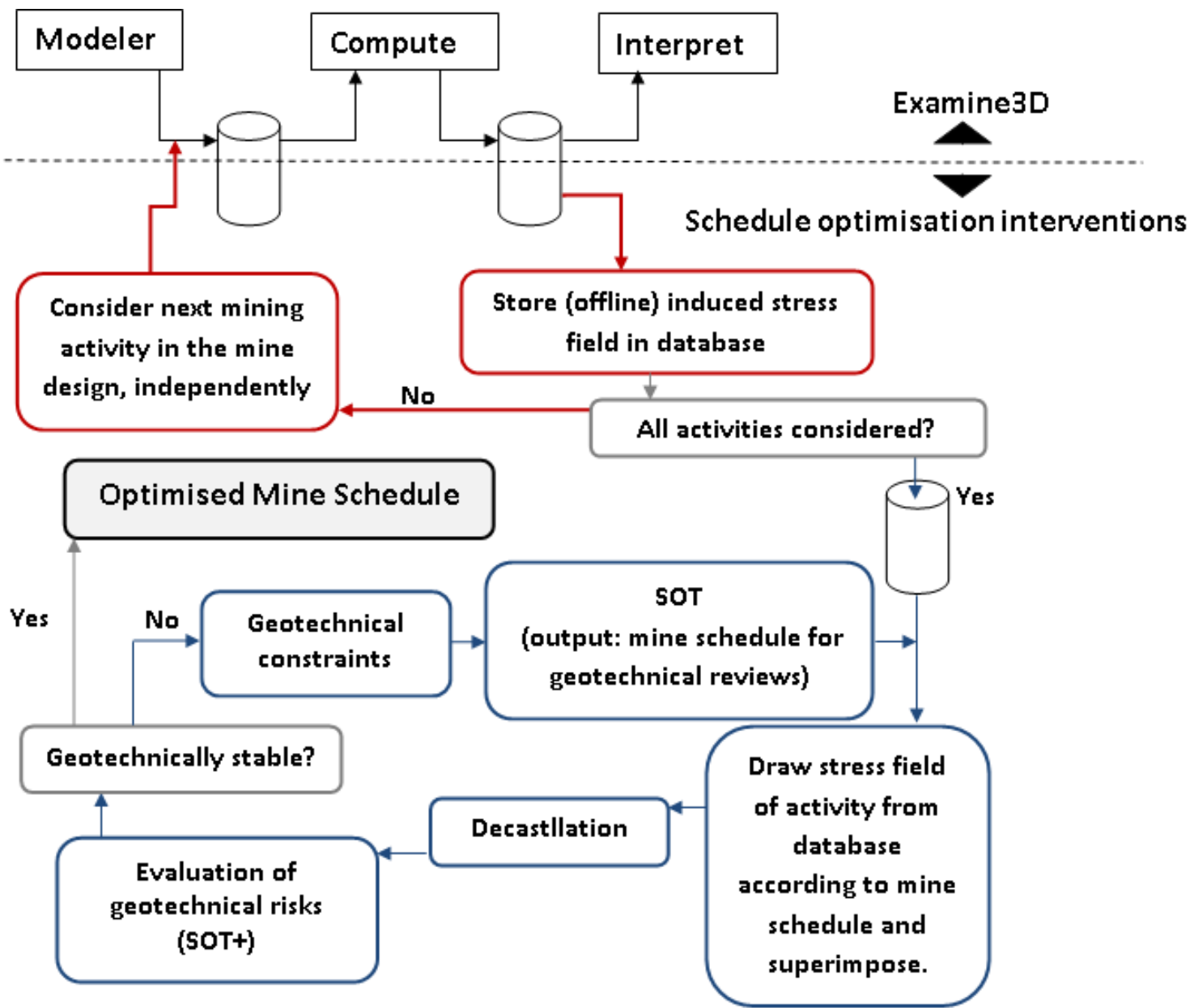

Figure 16 Scheme of geotechnical analyses in an automated fashion

\section{Acknowledgements}

This research is supported by a grant from the Ontario Centres of Excellence (OCE), as part of a program of work supported by Vale Canada and CAE Mining.

\section{References}

Adams, GR \& Jager, AJ 1980, 'Petroscopic observations of rock fracturing ahead of stope faces in deep-level gold mines', African Institute of Mining and Metallurgy, vol. 44, pp. 204-209.

Beneteau, DL 2012, M.Sc. thesis, 'A study relating Time-Between-Events (TBE) to seismic source mechanisms in hard rock mining', Laurentian University, Sudbury.

Bieniawski, ZT 1976, 'Rock mass classification in rock engineering', in ZT Bieniawski (ed.), Proceedings of the Symposium on Exploration for Rock Engineering, A.A. Balkema, Rotterdam, pp. 97-106.

Brady, B \& Brown, E 1993, Rock Mechanics: for underground mining, 3rd edn, Kluwer Academic Publishers, Dordrecht.

Denkhaus, HG, Hill, FG \& Roux, AJA 1958, 'A review of recent research into rockbursts and strata movement in deep-level mining in South Africa', Association of Mine Managers, pp. 245-268.

Dusseault, MB \& Fordham, CJ 1993, 'Time-dependent behavior of rocks', in JA Hudson (ed.), Comprehensive Rock Engineering, Pergamon Press, Oxford.

Eberhardt, E, Stead, D, Reeves, M \& Connors, C 1997, 'Design of tabular excavations in foliated rock: an integrated numerical modeling approach', Journal of Geotechnical and Geological Engineering, vol. 15, pp. 47-85.

Hoek, E \& Brown, E 1987, Underground excavation in rock, Institution of Mining and Metallurgy, England.

Houwink, R \& de Decker, HK 2009, Elasticity, plasticity and structure of matter, Cambridge University Press, Cambridge.

King, RG, Jager, AJ, Roberts, MKC \& Turner, PA 1989, Rock mechanics aspects of stoping without back-area support, no. 17/89: COMRO (now CSIR Miningtek) research report, CSIR Miningtek, Pretoria.

Lakes, RS 2009, Viscoelastic materials, Cambridge University Press, Cambridge.

Linkov, AM 1996, 'Rockbursts and the instability of rock masses', International Journal of Rock Mechanics and Mining Sciences \& Geomechanics Abstracts, vol. 33, pp. 727-732. 
Louchnikov, V 2004, M.Sc. thesis, 'A numerical investigation into the stress memory effect in rocks', University of Adelaide, Adelaide.

Malan, DF 1999, 'Time-dependent behavior of deep level tabular excavations in hard rock', Rock Mechanics and Rock Engineering, vol. 32, no. 2, pp. 123-155.

Malan, DF 2003, Guidelines for measuring and analyzing continuous stope closure behavior in deep tabular excavations, The Safety in Mines Research Advisory Committee (SIMRAC), South Africa.

Maybee, B, Fava, L, Dunn, PG, Wilson, S, Fitzgerald, J 2010, 'Toward optimum value in underground mine scheduling', Canadian Institute of Mining and Petroleum, vol. 1, no. 3, pp. 176-182.

Meyers, MA \& Chawla, KK 1999, Mechanical behavior of materials, Prentice Hall, Upper Saddle River.

Millar, DL \& Jiao, Y 1994, 'On the use of genetic algorithms in modelling the deformability behaviour of rock', Riccione, IV convegno dei giovani ricercatori in geologia applicata, vol.1, pp. 25-43.

Morrison, D 1995, 'Fragmentation - the future', Proceedings of EXPLO 95: Exploring the Role of Rock Breakage in Mining and Quarrying, Australian Institute of Mining and Metallurgy, Carlton, pp. 11-18.

Ranalli, G 1987, Rheology of the earth: deformation and flow processes in geophysics and geodynamics, Allen \& Unwin, Crows Nest.

Rocscience inc. 2014a, Phase2: Finite Element Analysis for Excavations and Slopes², Rocscience inc., Toronto, http://www.rocscience.com/products/3/Phase2

Rocscience inc. 2014b, Examine 3D: Engineering Analysis for Underground Excavations, Rocscience inc., Toronto, http://www.rocscience.com/products/2/Examine3D

Roux, AJA \& Denkhaus, HG 1954, 'An investigation into the problem of rockbursts, an operational research project', Chemical and Metallurgical Society of South Africa, vol. 55, pp. 103-124.

Terry, NB \& Morgans, WTA 1958, 'Studies on the rheological behavior of coal', in WH Walton (ed.), Mechanical properties of non-metallic brittle materials, Butterworths Scientific, London.

Villaescusa, E 2003, 'Global extraction sequences in sublevel stoping', Proceedings of the Twelfth International Symposium on Mine Planning and Equipment Selection: MPES 2003, Australasian Institute of Mining and Metallurgy, Carlton. 